\title{
Factors associated with high risk of marginal hyperthermia in elderly patients living in an institution
}

\author{
Michael Vassallo, Kevin Navarro Gera, Steve Allen
}

\begin{abstract}
Summary
The elderly, the very young, and the sick are known to be adversely affected by high environmental temperatures. In a retrospective open case-note review of 872 patients in a large institution during a hot summer we identified characteristics in the elderly that increase the risk of marginal hyperthermia. Women were more likely to be affected than men $(25.6 \%$ vs $16.9 \%)$. We found an age-related increase in marginal hyperthermia, $15.7 \%$ of those below 60 years developed a hyperthermia compared to $18.9 \%$ in those between 70-79 years (non-significant), $28.3 \%$ in those between 80-89 years $(p=0.01)$ and $50 \%$ in those above 90 years $(p<0.01)$. There was also a direct relationship between the incidence of hyperthermia and the ambient temperature $(29 \%$ in the warmer wards, compared to $17.2 \%$ in cooler ones; $p<0.01$ ) and with the level of dependence $(42.3 \%$ of the bedridden group, $p<0.01$, and $20.4 \%$ of the semidependent, $p<0.01$, compared to $11.1 \%$ of the mobile group). These factors were more significant as predictors of risk than the diagnosis. Identifying high risk patients early and taking appropriate measures to avoid hyperthermia and dehydration is important to try to decrease mortality during heatwaves.
\end{abstract}

Keywords: hyperthermia, elderly, thermoregulation

\section{Introduction}

Department of Medicine for the Elderly, Royal Bournemouth Hospital, Castle Lane East, Bournemouth BH7 7DW, UK

$M$ Vassallo

KN Gera

$S$ Allen

Correspondence to

Dr Michael Vassallo, Senior Registrar Integrated

Medicine, Leicester General Hospital, Gwendolen Road, Leicester LE5 4PW, UK

Accepted 23 November 1994 sweating is lower than that of young people. Coexisting heart and cerebrovascular disease impairs their ability to increase cardiac output
External temperature at both extremes increases mortality in elderly people. ${ }^{1-3}$ the intrinsic regulatory system or because of the presence of drugs that interfere with normal impaired thermoregulatory system to cope with ${ }^{4}$ Elderly people do not acclimatize well to external temperatures. ${ }^{5}$ They are less res sive to changes in external temperature; their sweating threshold is higher and their rate of and decrease sympathetic vascular resistance during hot weather. ${ }^{5}$ The core temperature threshold for vasodilatation may increase with age. ${ }^{6}$ Drugs that affect the autonomic nervous system and interfere with vasodilatation and sweating also increase the risk of heat related illness. Mortality is high once an elderly person develops severe heat illness ${ }^{7}$ so it is important to try to identify risk factors to improve the detection of high-risk groups. Peaks in daily mortality in nursing homes lagged behind the corresponding peaks in maximum temperature by one day. ${ }^{6}$ Since mortality is highest at the beginning of heatwaves it is essential that quick action is taken to achieve a reduction in mortality.

Malta has a subtropical climate with hot and dry summers. We tried to identify predisposing factors by retrospectively studying 872 patients of various ages lodged in a large institution during a particularly hot summer in Malta.

\section{Patients and methods}

The institution studied served as a hospital, nursing home, residential home, and sheltered accommodation for its residents, housing people of varying degrees of disability, mostly $(87 \%$ ) being elderly ( $>60$ years) and institutionalised for various reasons, ranging from severe disabling disease such as strokes to normal healthy people admitted for social reasons.

We performed a retrospective open casenote review to identify those who were resident during the study period. We also examined the notes of the people who died during that time period. Of 872 patients identified 114 were less than 60 years and 758 were above. Average age was 73 years with a range from 30 to 98 . The younger group had proportionately similar levels of physical disability to the elderly group. Evidence of marginal hyperthermia was defined as temperature of $38^{\circ}$ Celsius $\left(100^{\circ}\right.$ Fahrenheit) or more recorded orally, or if not possible axillary, on at least one occasion. For all the patients in the study we recorded age, sex, and ward location, subdividing them into top floor or isolated buildings considered warmer with no shade from direct sunlight, and ground floor, considered cooler since they were partly shaded from direct sunlight. We also looked at diagnoses and level of dependence. We defined bedridden as being unable to get 
out of bed unaided, semidependent as requiring help with at least one measure of activities of daily living, and mobile as able to walk alone even if they used walking aids.

Daily readings of the peak temperature in the shade and humidity were obtained for the study period and the average weekly value for both was derived.

For febrile patients we tried to identify a cause for the hyperthermia by looking at the clinical records and investigation results. There was no infectious disease epidemic at the time and, since the incidence of episodes of hyperthermia correlated with external temperature $(r=0.64 ; \mathrm{p} \mathrm{0.04})$, for the purposes of this study we assumed that all the episodes of hyperthermia were directly or indirectly related to the heat stress and were included in the results.

\section{Statistical methods}

Correlation analysis was performed between external temperature, humidity, episodes of hyperthermia, male and female deaths. The associations between prevalence of hyperthermia, age, sex, diagnosis and state of dependence were examined using regression analysis. Patient groups were compared using the Yates' Chi-square test.

\section{Results}

There was a significant correlation between the external temperature and number of cases of hyperthermia $(r=0.64, p=0.04)$. Humidity was negatively correlated to external temperature $(r=-0.75, p<0.05)$, but did not show any significant relationship to number of deaths or hyperthermia $(r=-0.55,-0.38)$. Out of 268 febrile illnesses $67.6 \%$ were attributed to the higher external temperature, $19 \%$ to respiratory infections, $8.5 \%$ to urinary infections and $4.9 \%$ to other causes, including infected bed sores, gastroenteritis, and typhus fever. The difference between men and women was not significant when allowing for disability and specific illness but regression analysis showed that women were affected more than men $(p<0.05)$ when allowing for age, a fact reflected in mortality figures, though the difference was not significant $(p>0.05)$ (table 1). We found that there was a progressively increased susceptibility to febrile illness as one grew older (table 2), reaching significance $(p<0.01)$ in those above 80 years. The increase in susceptibility in the 90-99 age group was significantly more than the 80-89 group $(\mathrm{p}<0.05)$. Bedridden patients were the most susceptible to marginal hyperthermia compared to both semidependent $(p<0.01)$ and mobile groups $(p<0.01)$ (table 3$)$. Patients who had the same underlying diagnosis had significantly more febrile illness if bedridden rather than if mobile. This pattern was observed in conditions that specifically affect temperature regulation and other conditions that may have an indirect role to play. Hence state of mobility seemed to be a more important predictor than the diagnosis itself (table 5). Patients resident in warm wards were also more likely to be affected by marginal hyperthermia $(\mathrm{p}>0.01$ ) (table 4).

\section{Discussion}

'Heat waves' have no precise meteorological definition and are usually determined by what is regarded as local temperature conditions. ${ }^{6}$ We studied a Maltese summer with exceptionally high peak daily shade temperatures: $6-12^{\circ} \mathrm{C}$ higher than average for the time of year. Since this study was retrospective, we had no control group and we could only look at one manifestation of heat-related illness, hyperthermia. Data on the state of hydration such as urine and plasma osmolarity were only available in a few patients. The high body temperature could have been due to reasons other than the high environmental temperatures; however, since there was a close relationship between the incidence of hyperthermia and external temperature, and there were no infectious disease epidemics on reviewing microbiological culture and serological results, and high environmental temperatures are known to predispose to repiratory infection, ${ }^{1}$ the commonest recorded cause for the cases of hyperthermia noted, it was assumed that virtually all pyrexias recorded were directly or indirectly related to, or affected by, the external temperature, and all were included in the study.

There was an increased incidence of marginal hyperthermia in the female group. This finding, together with our mortality figures is compatible with the findings of Macey et $a l^{8}$

Table 1 Distribution of female and male deaths and cases of hyperthermia in relation to date and average maximum weekly temperature and humidity

\begin{tabular}{|c|c|c|c|c|c|c|c|c|c|c|c|c|c|c|}
\hline & \multicolumn{14}{|c|}{ Week } \\
\hline & $\begin{array}{l}21- \\
27 / 6\end{array}$ & $\begin{array}{c}28 / 6- \\
4 / 7\end{array}$ & $\begin{array}{c}5- \\
11 / 7\end{array}$ & $\begin{array}{l}12- \\
18 / 7\end{array}$ & $\begin{array}{l}19- \\
25 / 7\end{array}$ & $\begin{array}{c}26 / 7- \\
1 / 8\end{array}$ & $\begin{array}{l}2- \\
8 / 8\end{array}$ & $\begin{array}{c}9- \\
15 / 8\end{array}$ & $\begin{array}{l}16- \\
22 / 8\end{array}$ & $\begin{array}{l}23- \\
29 / 8\end{array}$ & $\begin{array}{c}30 / 8- \\
5 / 9\end{array}$ & $\begin{array}{c}6- \\
12 / 9\end{array}$ & $\begin{array}{l}13- \\
19 / 9\end{array}$ & $\begin{array}{l}20- \\
26 / 9\end{array}$ \\
\hline $\begin{array}{l}\text { Temperature } \\
\left({ }^{\circ} \mathrm{C}\right)^{\star} \\
\text { Humidity }\end{array}$ & 25.8 & 29.1 & 31.8 & 32.1 & 36.8 & 32.1 & 30.2 & 36.7 & 30.7 & 30.8 & 29.8 & 29.8 & 30.5 & 31.5 \\
\hline $\begin{array}{c}(\%) \\
\text { No with }\end{array}$ & 60.4 & 53.4 & 57 & 48.2 & 39.5 & 56.7 & 60.8 & 41.7 & 64.2 & 67.2 & 64.1 & 57.5 & 58.8 & 52.8 \\
\hline hyperthermia & 4 & 2 & 7 & 10 & 43 & 63 & 31 & 51 & 26 & 13 & 8 & 6 & 2 & 2 \\
\hline Male deaths & 3 & 1 & 1 & 1 & 3 & 4 & 1 & 2 & 1 & 1 & 0 & 0 & 1 & 2 \\
\hline Female deaths & 3 & 5 & 2 & 4 & 18 & 4 & 4 & 3 & 4 & 5 & 1 & 3 & 6 & 2 \\
\hline Total deaths & 6 & 6 & 3 & 5 & 21 & 8 & 5 & 5 & 5 & 6 & 1 & 3 & 7 & 4 \\
\hline
\end{tabular}

^Average peak weekly temperature; ${ }^{\star}$ average weekly humidity 
Table 2 Comparing patients with hyperthermia to sex and age group

\begin{tabular}{|c|c|c|c|c|c|c|}
\hline \multirow[b]{2}{*}{$\begin{array}{l}\text { Age group } \\
\text { (years) }\end{array}$} & \multicolumn{2}{|c|}{ Males } & \multicolumn{2}{|c|}{ Females ${ }^{\star \star}$} & \multicolumn{2}{|c|}{ Combined } \\
\hline & $n$ & $\begin{array}{l}\text { No with } \\
\text { hyperthermia (\%) }\end{array}$ & $n$ & $\begin{array}{l}\text { No with } \\
\text { hyperthermia (\%) }\end{array}$ & $n$ & $\begin{array}{l}\text { No with } \\
\text { hyperthermia (\%) }\end{array}$ \\
\hline$<60$ & 37 & $8(21)$ & 77 & $10(13)$ & 114 & $18(15.7)$ \\
\hline $60-69$ & 62 & $6(9)$ & 84 & $17(20)$ & 146 & $23(15.7)$ \\
\hline $\begin{array}{l}70-79 \\
\left(p>0.05^{\star}\right)\end{array}$ & 106 & $17(16)$ & 173 & $36(20)$ & 279 & $53(18.9)$ \\
\hline $\begin{array}{l}80-89 \\
\left(p=0.01^{\star}\right)\end{array}$ & 82 & $16(19)$ & 193 & $62(32)$ & 275 & $78(28.3)$ \\
\hline $\begin{array}{l}90-99 \\
\left(\mathrm{p}<0.01^{\star}\right)\end{array}$ & 10 & $3(30)$ & 48 & $26(54)$ & 58 & $29(50.0)$ \\
\hline
\end{tabular}

*Comparing age group with control group below 60 years; ${ }^{\star \star}$ Comparing female to male group with age as a continuous variable; $\mathrm{p}<0.05$

who found a strong female bias for deaths from excessive heat. Females have a genetic trait responsible for lower sweat rates though the increased fat content in females may be an important predisposing factor. Our mortality figures show that the highest mortality occurred at the beginning of the hottest period and decreased thereafter despite persistent hot temperatures. This is probably because the most susceptible died early in the hot period. Also, others probably began to acclimatize and contingency plans to deal with the problem by providing extra cold drinks, suitable clothing and cooling equipment started operating. This same pattern of early mortality was recorded by Katsouyanni et al' under very similar circumstances in Athens.

Table 3 Distribution of temperature by bed state comparing groups to the mobile (control) group

\begin{tabular}{llll}
\hline & Bedridden & Semi-dependent & Mobile \\
\hline Febrile/total & $108 / 255$ & $45 / 220$ & $44 / 397$ \\
$\%$ Febrile & $42.3^{\star}$ & $20.4^{\star}$ & 11.1 \\
\hline${ }^{\star} \mathrm{p}<0.01$ & & &
\end{tabular}

Table 4 Ward location

\begin{tabular}{lcc}
\hline & $\begin{array}{l}\text { Top floor wards and } \\
\text { isolated buildings } \\
\text { (warm environment) }\end{array}$ & $\begin{array}{l}\text { Ground floor wards } \\
\text { (cool environment) }\end{array}$ \\
\hline$n$ & 396 & 476 \\
Patients with hyperthermia & 115 & 82 \\
$\%$ with hyperthermia & $29 \star$ & 17.2 \\
\hline
\end{tabular}

${ }^{\star} \mathrm{p}<0.01$
We found that there is an increased susceptibility to death from heat stress as one grows older; this risk being most marked in the very old. Mortality figures from three Los Angeles hot spells ${ }^{10}$ show that while the overall mortality was two to four times higher than background rate in the general population it was eight times the background rate in those over 85 years, again suggesting the risk is highest in the very old.

Level of dependence was an important predictor of susceptibility to marginal hyperthermia. There was a significantly higher incidence of hyperthermia in bedridden patients compared to the mobile group. The

\begin{tabular}{|l|}
\hline Risk factors for heat stress \\
\hline - environmental and room temperature \\
- female old age ( $>80$ years) \\
- state of dependence (bedridden $>$ semi- \\
dependent $>$ mobile) \\
- drugs, especially phenothiazines, \\
antidepressants, alcohol, diuretics \\
medical conditions: \\
cardiovascular: congestive heart failure, \\
ischaemic heart disease \\
neurological: cerebrovascular disease, \\
autonomic impairment, head injury, \\
cerebral tumour or abscess \\
mental condition: dementia, confusional states \\
endocrine: hyperthyroidism, diabetes \\
mellitus, hyperpituitarism \\
skin disorders: impairing sweating \\
infections: respiratory, gastrointestinal and \\
septicaemia
\end{tabular}

Table 5 Hyperthermia in relation to diagnosis and state of dependence

\begin{tabular}{|c|c|c|c|c|c|c|c|}
\hline & Bedridden & Semi-dependent & Mobile & Febrile/total & $\%$ Febrile & $\star$ & $\star \star$ \\
\hline & Febrile/afebrile & Febrile/afebrile & Febrile/afebrile & & & & \\
\hline Ischaemic heart disease & $55 / 77$ & $18 / 84$ & $21 / 142$ & $94 / 397$ & 23 & NS & $\mathrm{p}<0.01$ \\
\hline Congestive heart failure & $40 / 38$ & $8 / 42$ & $18 / 69$ & $66 / 215$ & 30 & NS & $\mathrm{p}<0.01$ \\
\hline Hypertension & $28 / 46$ & $6 / 43$ & $14 / 96$ & $48 / 233$ & 20 & NS & $\mathrm{p}<0.01$ \\
\hline Chronic airflow limitation & $10 / 11$ & $6 / 18$ & $5 / 61$ & $21 / 111$ & 18 & NS & $\mathrm{p}<0.01$ \\
\hline Cerebrovascular accident & $22 / 35$ & $4 / 20$ & $1 / 19$ & $27 / 101$ & 26 & NS & $\mathrm{p}<0.05$ \\
\hline Psychiatric & $4 / 10$ & $6 / 32$ & $5 / 56$ & $15 / 113$ & 13 & NS & NS \\
\hline Dementia & $39 / 44$ & $13 / 28$ & $3 / 49$ & $55 / 176$ & 31 & $\mathrm{p}<0.01$ & $\mathrm{p}<0.01$ \\
\hline Mental retardation & $12 / 21$ & $6 / 6$ & $5 / 18$ & $23 / 68$ & 33 & NS & NS \\
\hline Diabetic & $19 / 41$ & $7 / 54$ & $13 / 91$ & $39 / 225$ & 17 & NS & $\mathrm{p}<0.01$ \\
\hline
\end{tabular}

*Comparing the semi-dependent to the mobile group; ${ }^{\star \star}$ comparing the bedridden to the mobile group. NS = non-significant 


\section{Learning points}

- peak mortality occurs at the beginning of heatwaves and mortality is high once the elderly person develops heat illness

- early identification of high risk groups both in hospital and especially community setting is essential to reduce mortality

- take appropriate preventive measures: monitoring temperature and ensuring a cool room temperature

plentiful supply of cold drinks

cold meals like salads

light, loose clothing

avoid heavy exercise in direct sunlight

semidependent group also showed an increased incidence compared to the mobile group. This pattern was observed in patients both with identified conditions known to contribute to hyperthermia such as ischaemic heart disease, congestive heart failure, cerebrovascular disease, diabetes mellitus, mental retardation, and dementia, ${ }^{6}$ and other conditions such as hypertension and chronic airflow limitation. Hypertension may have an indirect effect on thermoregulation due to an increased incidence of cerebrovascular and cardiovascular disease and drugs used in its treatment such as diuretics. Chronic airflow limitation may increase susceptibility to respiratory tract infections during periods of high environmental temperature. Our findings also suggest that the

1 Godlee F. Health implications of climatic change. $B M \mathcal{F}$ 1991; 303: 1254-6.

2 Salvage AV. Old people in hot weather. Age Ageing 1991; 20: 233-5.

3 Bull GM, Morton J. Environment, temperature and death rates. Age Ageining 1978; 7: 210-24.

4 Collins KJ, Exton-Smith AN. Thermal haemostasis in old age. $\mathcal{A}$ Am Geriat Soc 1983; 31: 519-24.

5 Ellis EP. Mortality from heat illness and heat aggravated Ellis EP. Mortality from heat illness and heat aggravated

6 Collins KJ. Temperature haemostasis and thermal stress. In: Grimley Evans J, Williams TF, eds. Oxford textbook of geriatric medicine, Oxford: Oxford Medical Publications, 1992; pp 93-100. state of dependence is a more important predictor of risk of marginal hyperthermia than the diagnosis itself. Large hospital buildings in hot climates are likely to have some wards warmer than others for various reasons, we therefore looked at the incidence of heat-related stress in warmer and cooler wards. The warmer wards were isolated buildings or top floor wards that were exposed to continuous sunlight throughout the day without any shade. The results show that patients in such wards were affected to a greater extent, hence the need to identify such areas and to take steps to protect patients at times of exceptionally high environmental temperatures.

This study differs from many previously published studies in looking mostly at the survivors rather than the casualties of a hot period. Since mortality seems to be highest at the start of a hot spell, ${ }^{9}$ carers must act quickly to minimise morbidity and mortality, hence the need to target those elderly patients with the highest risk profile; that is, the very old and immobile. Lye and Kamal ${ }^{11}$ recommended the monitoring of body temperature of ill patients between 13.00 and $16.00 \mathrm{~h}$ during heat waves. Monitoring of room temperature would also alert carers to the risk of heat-related stress and prompt the provision of lighter clothing, cold food and drinks, and increase ventilation.

The authors wish to acknowledge the assistance of $\mathrm{Mr}$ Paul Vassallo for his help with the collection of data.

7 Robbins AS. Hypothermia and heat stroke: protecting the elderly patient. Geriatrics $1989 ;$ 44: 73-80.

8 Macey SM, Schneider DF. Deaths from excessive heat and excessive cold among the elderly. Gerontologist 1993; 33: excessive

9 Katsouyanni K, Trichopoulos D, Zavitsanos X, Touloumi G. The 1987 Athens heatwave. [letter] Lancet 1988; ii: 573 . 10 Oeschli FW, Buckley RW. Excess mortality associated with 10 Oeschli FW, Buckley RW. Excess mortality associated with 3: $277-84$.

11 Lye M, Kamal A. Effects of a heat wave on mortality-rates in elderly inpatients. Lancet 1977; i: 529-31. 